\title{
Implantation site intermediate trophoblasts in placenta cretas
}

\author{
Kyu-Rae Kim ${ }^{1}$, Sun-Young Jun ${ }^{1}$, Ji-Young Kim² and Jae Y Ro ${ }^{1}$ \\ ${ }^{1}$ Department of Pathology, Asan Medical Center, University of Ulsan College of Medicine, Seoul, Korea and \\ ${ }^{2}$ Department of Pathology, Cha General Hospital, College of Medicine Pochun Cha University, Seoul, Korea
}

\begin{abstract}
Placenta cretas are defined as abnormal adherences or ingrowths of placental tissue, but their pathogenetic mechanism has not been fully explained. During histologic examination of postpartum uteri, we noticed that the number of implantation site intermediate trophoblasts was increased in the placental bed of placenta cretas. To validate our observation and to address the pathogenetic role of implantation site intermediate trophoblasts in placenta cretas, we examined postpartum uteri with placenta cretas $(n=34)$ and noncretas $(n=22)$, obtained from Cesarean or immediate postpartum hysterectomy specimens. Using antibody to CD146, a marker for implantation site intermediate trophoblasts, we found that placenta cretas had significantly thicker layer of implantation site intermediate trophoblasts $(2300 \pm 1200 \mu \mathrm{m})$ than noncretas $(1500 \pm 1200 \mu \mathrm{m}, P<0.025)$. We also observed that the confluent distribution of cells was more frequent in placenta cretas (97\%) than noncretas samples $(45 \%, P<0.001)$, and that the total number of implantation site intermediate trophoblasts within the superficial myometrium of the placental bed was significantly higher in placenta cretas than noncretas. Using antibodies to $\mathrm{Ki}-67, \mathrm{Bcl}-2$ and cleaved caspase-3 to determine the proliferative index and apoptotic rates of implantation site intermediate trophoblasts, we found that they were close to zero in both groups and did not differ significantly. These findings suggest that the increased number of implantation site intermediate trophoblasts observed in placenta cretas may be related to the pathogenesis of placental ingrowth, but the mechanism by which the increase in implantation site intermediate trophoblasts causes placenta cretas remains to be clarified.
\end{abstract}

Modern Pathology (2004) 17, 1483-1490, advance online publication, 18 June 2004; doi:10.1038/modpathol.3800210

Keywords: placenta cretas; intermediate trophoblast; implantation site; CD146

Placenta cretas, including placenta acreta, increta, and percreta, are defined as abnormal adherences and/or ingrowths of the placenta to the uterine wall, such that clear separation of the placenta does not occur after the delivery of the newborn. ${ }^{1}$ Although deficient or absent endometrial decidualization with a subsequent abnormal trophoblastic invasion into the nonfundic implantation site or scarred endometrium has been suggested to be important in the pathogenesis of placenta cretas, ${ }^{2,3}$ the exact mechanisms for the abnormal adherence and ingrowth of placental tissue have not been fully elucidated.

Intermediate trophoblasts in normal gestation have been subdivided into villous intermediate

Correspondence: Dr K-R Kim, MD, Department of Pathology, University of Ulsan College of Medicine, Asan Medical Center, 388-1, Pungnap-dong, Songpa-gu, Seoul 138-736, Korea.

E-mail: krkim@amc.seoul.kr

A part of this work was presented as a platform presentation at the 92nd annual meeting of the USCAP, Washington, DC, March 2003. Received 13 February 2004; revised 17 May 2004; accepted 19 May 2004; published online 18 June 2004 trophoblasts, implantation site intermediate trophoblasts (ISITs) and chorionic-type intermediate trophoblasts, depending on their locations, cytomorphologic features, growth patterns, and the immunohistochemical phenotypes. ${ }^{4-6}$ ISITs can infiltrate the decidua, spiral arterioles, and myometrium and these cells play a major role in the establishment of maternofetal circulation during early pregnancy. The invasive properties of ISITs have been observed in the implantation sites of early abortuses and normal postpartum uteri, as well as in non-neoplastic and neoplastic lesions, including exaggerated placental site reactions and placental site trophoblastic tumors.

CD146, a recently described cell adhesion molecule belonging to the immunoglobulin gene superfamily, has been reported to function in the processes of tumor progression, metastasis, implantation, and placentation. ${ }^{4,5,7}$ The finding that CD146 is expressed by intermediate trophoblasts at implantation sites has made it a useful marker for ISITs. $^{4,5,7,8}$

During the examination of Cesarean hysterectomy specimens, we observed that there were more ISITs 
in the placental bed of placenta cretas than in normal implantation sites, suggesting that there may be a relationship between the invasive properties of ISITs and the pathogenetic mechanism of placenta cretas. We have therefore sought to quantitate ISITs by their thickness, number, and distribution pattern within the myometrium, as well as to determine the number of proliferating and apoptotic ISITs in the superficial myometrium of placenta cretas and noncretas.

\section{Materials and methods}

\section{Selection of Cases and Clinical Features}

Tissue specimens from 60 women who underwent hysterectomies during third trimester pregnancies were retrieved from the surgical pathology files of the Department of Pathology at the Asan Medical Center, Seoul, Korea, between January 1995 and March 2002, and of the Cha General Hospital, Seoul, Korea, between March 2001 and July 2002. All uteri were obtained from Cesarean or immediate postpartum hysterectomies within $48 \mathrm{~h}$ after delivery. To make sure that the implantation sites were properly sampled for histological examination, four cases in which ISITs were not included on the slides were excluded from the study. The remaining 56 cases were classified as placenta cretas $(n=34)$ or noncretas $(n=22)$, depending on the presence or absence of a direct attachment or ingrowth of placental tissue to the myometrium on histologic examination. As many of the histologic sections did not include full thickness of myometrium, placenta cretas were not further subdivided into placenta accreta, increta, and percreta. Clinical records, including the age of the pregnant women, the number of weeks of gestation, and the indications for the hysterectomies, were reviewed in all patients. For comparison, we included three cases of ruptured tubal pregnancies which were positive for ISITs in the placental bed.

\section{Immunohistochemistry}

Immunohistochemical stainings were performed manually using a labeled streptavidin-biotin kit (DAKO Corporation, Carpinteria, CA, USA) and commercially available monoclonal antibodies to human CD146 (1:1000 dilution, Novocastra, New Castle, UK), Ki-67 (1:200 dilution, DAKO, Glostrup, Denmark), Bcl-2 (1:50 dilution, DAKO, Glostrup, Denmark), and cleaved caspase-3 antibody (1:200 dilution, Cell Signaling, Beverly, MA, USA). Briefly, formalin-fixed, paraffin-embedded archival tissues were sectioned to $4 \mu \mathrm{m}$ thickness at room temperature, dewaxed in xylene, and rehydrated in a graded ethanol series. To enhance immunostaining, heat epitope retrieval was performed by heating samples in buffered citric acid, $\mathrm{pH}$ 6.0, for $30 \mathrm{~min}$ in a steamer (Black and Decker, Hampstead, MD, USA) and allowing them to cool at room temperature for $30 \mathrm{~min}$. Endogenous peroxidase activity was quenched by incubating each specimen for $5 \mathrm{~min}$ in $0.3 \%$ hydrogen peroxide, and nonspecific staining was blocked by a 10-min incubation with blocking reagent. The samples were washed in buffer solution and incubated with the appropriate antibody.

\section{Maximum Intramyometrial Thickness of ISITs}

Following immunostaining of sections with the antiCD146 antibody, they were examined under the microscope, and the thickness of CD146-positive ISITs was measured as the distance between the ISITs in the most superficial layer and those in the deepest area within the myometrium using a micrometer. As the thickness of residual decidua was highly variable, ISITs within the deciduas were not counted.

\section{Distribution Patterns of ISITs}

Distribution patterns of the CD146-positive ISITs were recorded as 'confluent' or 'scattered'. Cases were considered 'confluent' when they formed a diffuse sheet-like arrangements, continuous cell cords, or large clusters occupying more than twothirds of the captured fields. In contrast, cases were designated 'scattered' when they were distributed individually or formed small groups of five or fewer cells.

\section{Number of Total and Multinucleated ISITs per Unit Area}

To compare the density of ISITs within the same thickness, the numbers of total and multinucleated ISITs, defined as cells having three or more nuclei, per unit area were separately counted in each sample. To count the numbers of total ISITs, CD146-immunostained sections were scanned at a low-power magnification to determine the areas showing the highest positive staining. Subsequently, five random areas per slide were viewed at $\times 100$ magnification using a microscope linked via a color CCD video camera (MW-Fi5E, Panasonic, Matsushita Electrical Industrial Co., Ltd, Osaka, Japan) to a personal computer with image analyzer software (Image-Pro Plus version 4.0 for Windows ${ }^{\mathrm{TM}}$, Media Cybernetics, Silver Spring, MD, USA). All files were saved in jpeg format and the mean numbers of CD146-immunopositive cells per sample were calculated by two pathologists who were blinded as to which sections were from placenta cretas and which were from noncretas. 


\section{Statistical Analysis}

Data were analyzed using the Statistical Package for the Social Sciences (SPSS, version 10.0, Chicago, IL, USA). Clinical features including the patient's age and the number of gestational weeks, ISIT thicknesses within the myometrium, the number of total and multinucleated ISITs, and the number of immunopositive cells for Ki-67, Bcl-2, and cleaved caspase- 3 between the placenta cretas and noncretas groups were compared using Student's $t$-test. The between-group differences in distribution pattern of CD146-positive ISITs, scored as 'confluent' or 'scattered', were compared by $\chi^{2}$ test. A probability $(P)$ value $\leq 0.05$ was considered statistically significant.

\section{Results}

\section{Clinical Features}

In the placenta cretas group, the patients ranged in age from 27 to 44 years (mean, 32.3 years), and the gestational ages ranged from 28 to 37 weeks. In the noncretas group, the patients ranged in age from 24 to 38 years (mean, 31.7 years), and the gestational ages ranged from 34 to 38 weeks (Table 1). All 34 patients with placenta cretas received hysterectomies because of heavy postpartum bleeding. Among the 22 patients with noncretas, seven patients received emergency hysterectomies due to postpartum bleeding caused by placental remnants (three cases) or uterine atony (four cases), but the causes of uterine atony were not further specified. Of 15 noncretas patients who received elective Cesarean hysterectomies, four had placenta previas, four had leiomyomas, two had ovarian carcinomas, one had a uterine prolapse, one had a double uterus, and one had adenomyosis; for the remaining two patients, the causes were not specified. The number of examined slides per uterus ranged from 4 to 9 (mean, 5.6). Of the 22 noncretas cases, histological examination of the placentas showed that 18 had intact maternal surfaces. The other four were examined by the obstetrician at the time of delivery, and each was recorded as unremarkable.

\section{Pathologic and Immunohistochemical Findings of the Implantation Sites}

In the placenta cretas samples, placental tissue showed variable and irregular ingrowth into the myometrium, resulting in irregular, undulated placental-myometrial interfaces. Within the myometrium, ISITs formed confluent sheets, irregular clusters, or continuous cords (Figure 1a). Most were mononucleated with round to ovoid nuclei. Mitotic figures were not identified (Figure 1b). They have abundant amphophilic cytoplasm closely resembling the decidual cells. In noncretas samples, the deciduas contained numerous ISITs, both monoand multinucleated, but within the adjacent myometrium the number of ISITs decreased abruptly, with only a few, scattered, multinucleated ISITs (Figure 2).

On hematoxylin and eosin-stained sections, it was difficult to distinguish ISITs from decidual cells and hypertrophic smooth muscle fibers because of their common nuclear atypicalities with similar nuclear sizes and shapes, and abundant cytoplasm. In the CD146-immunostained sections, however, ISITS were clearly distinguished from other cell types by their distinct membrane staining and frequent multinucleation (Figure 3a and b). Some of the smooth muscle fibers were weakly immunopositive for CD146, but the positive reactions were faint and mostly seen in the cytoplasm without membrane

Table 1 Clinical profiles, and histological and immunohistochemical parameters of placenta cretas and noncretas groups

\begin{tabular}{|c|c|c|c|}
\hline & Placenta cretas, $\mathrm{n}=34$ & Noncretas, $\mathrm{n}=22$ & $\mathrm{P}$-value \\
\hline Mean age (years) & 32 & 32 & NS \\
\hline Gestational ages (weeks) & $28-37$ & $34-38$ & NS \\
\hline Intramyometrial thickness of ISITs ${ }^{\mathrm{a}}(\mu \mathrm{m})$ & $2300 \pm 1200$ & $1500 \pm 1200$ & 0.025 \\
\hline Distribution patterns ${ }^{\mathrm{b}}$ & & & 0.001 \\
\hline Confluent & 33 & 10 & \\
\hline Scattered & 1 & 12 & \\
\hline Total number of ISITs ${ }^{\mathrm{a}}$ & $38 \pm 12$ & $19 \pm 10$ & 0.001 \\
\hline No. of multinucleated ISITs ${ }^{\mathrm{a}}$ & $14 \pm 25$ & $10 \pm 8$ & NS \\
\hline \multicolumn{4}{|l|}{ Immunopositivities } \\
\hline Ki-67 & Very rare & Very rare & NS \\
\hline Bcl-2 & Very rare & Very rare & NS \\
\hline Cleaved caspase-3 & Very rare & Very rare & NS \\
\hline
\end{tabular}

\footnotetext{
${ }^{\mathrm{a}}$ Values are mean \pm s.d.

balues are the number of cases.

NS, not significant; ISITs, implantation site intermediate trophoblasts.
} 

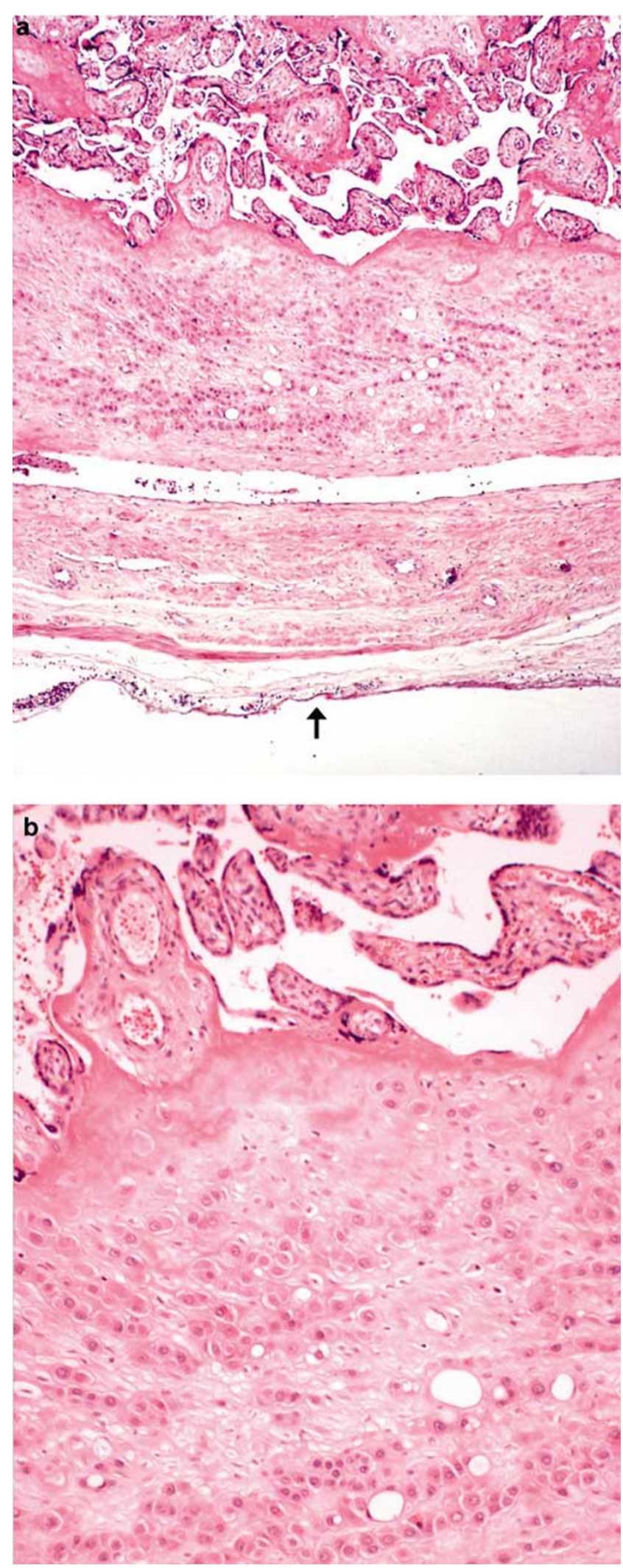

Figure 1 ISITs in placenta cretas. (a) They form confluent sheets or continuous cords in the deep myometrium (arrow indicates the uterine serosa). (b) They are predominantly mononucleated cells that have similar nuclear sizes, shapes, and abundant cytoplasm to decidual cells.

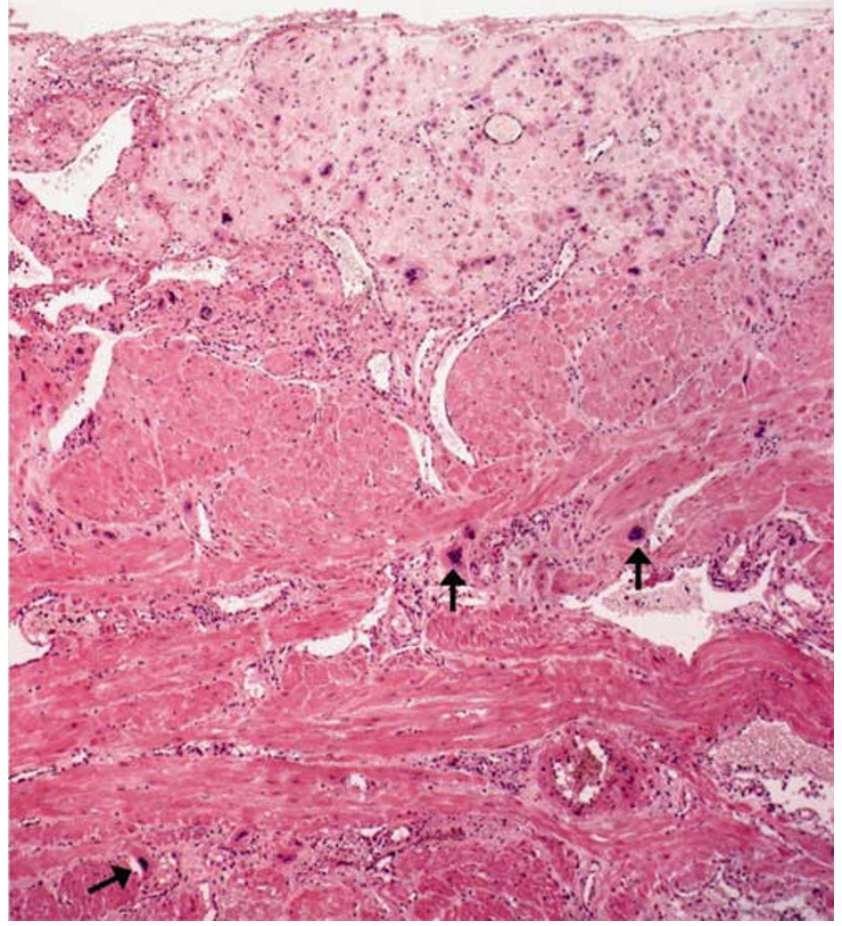

Figure 2 ISITs in noncretas. There are only a few scattered multinucleated ISITs within the superficial myometrium (arrow), although the decidua contain many mononucleated or multinucleated ISITs. Note abrupt decrease in the number of ISITs within the superficial myometrium.

staining. Decidual cells were similar to ISITs in size, but the former were usually mononucleated and completely immunonegative for CD146.

\section{Thickness of Intramyometrial CD146-Immunopositive ISITs}

The thickness of CD146-positive ISITs within the superficial myometrium ranged from 500 to $5500 \mu \mathrm{m}$ (mean, $2300 \pm 1200 \mu \mathrm{m}$ ) in cases of placenta cretas, and from 0 to $5000 \mu \mathrm{m}$ (mean, $1500 \pm 1200 \mu \mathrm{m}$ ) in noncretas $(P=0.025)$. (Figure 4$)$. In both groups, ISITs did not invade more than $5500 \mu \mathrm{m}$ beyond the most superficial layer.

\section{Distribution Patterns of ISITs}

The patterns of distribution were significantly different between the two groups $(P<0.001)$. In 33 of the 34 cases $(97 \%)$ of placenta cretas, ISITs formed confluent, diffuse sheets or large clusters. In contrast, 10 of the 22 cases $(45 \%)$ of noncretas showed confluent distribution of ISITs, with the remaining $12(55 \%)$ showing a 'scattered' pattern of ISITs within the superficial myometrium (Figure 5). 

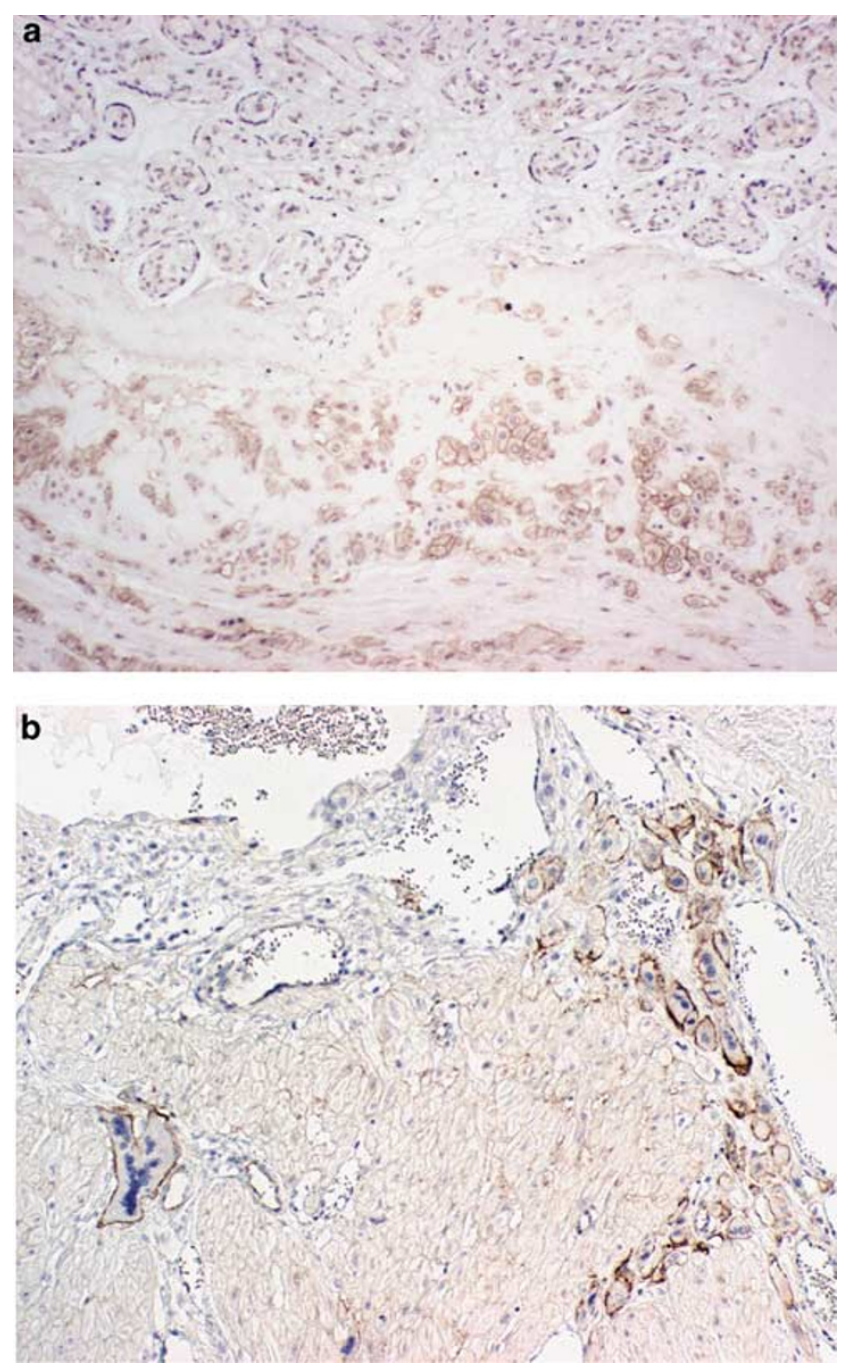

Figure 3 Immunohistochemical stain for CD146 in (a) placenta cretas and (b) noncretas showing a distinct membrane staining in ISITs. Note confluent distribution pattern in placenta cretas (a) and scattered pattern in noncretas (b).

\section{Number of Total and Multinucleated ISITs per Unit Area}

When we counted the number of total ISITs in $\times 100$ magnification fields, we found that it ranged from 15 to 74 (mean 38.2) in placenta cretas and from 7 to 41 in noncretas (mean 18.7) and the difference was statistically significant $(P<0.001)$ (Figure 6). The number of multinucleated ISITs in $\times 100$ magnification fields averaged 14.5 (range, 1-41) in the placenta cretas cases, and 10.3 (range, 1-31) in the noncretas cases, and the difference was not statistically significant $(P=0.364)$.

\section{Immunopositivities for Ki-67, Bcl-2, and Cleaved Caspase-3}

When we stained the placenta cretas samples with antibody to Ki-67, we observed one or two positive

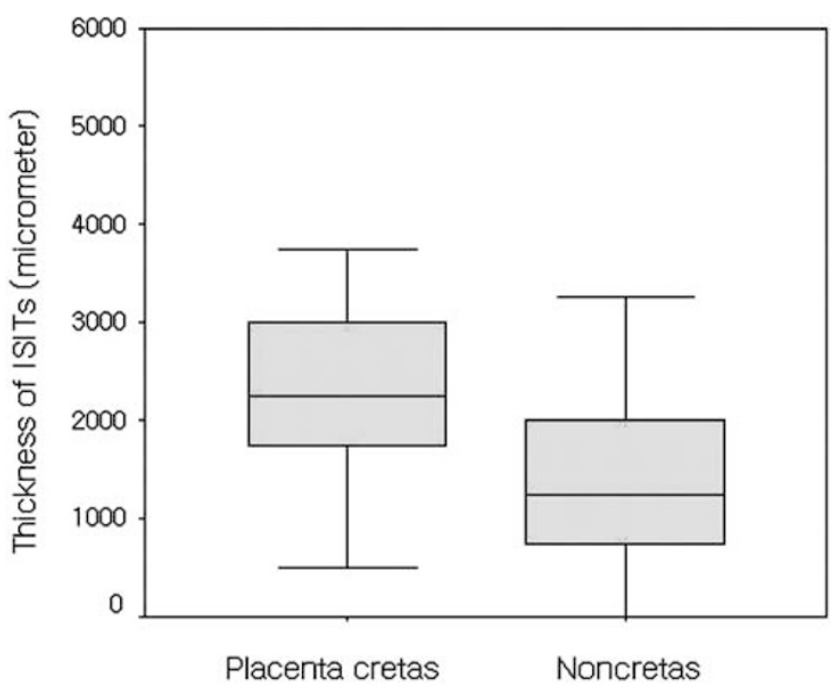

Figure 4 Thickness of CD146-positive ISITs in the superficial myometrium of placenta cretas and noncretas showing a significance difference.

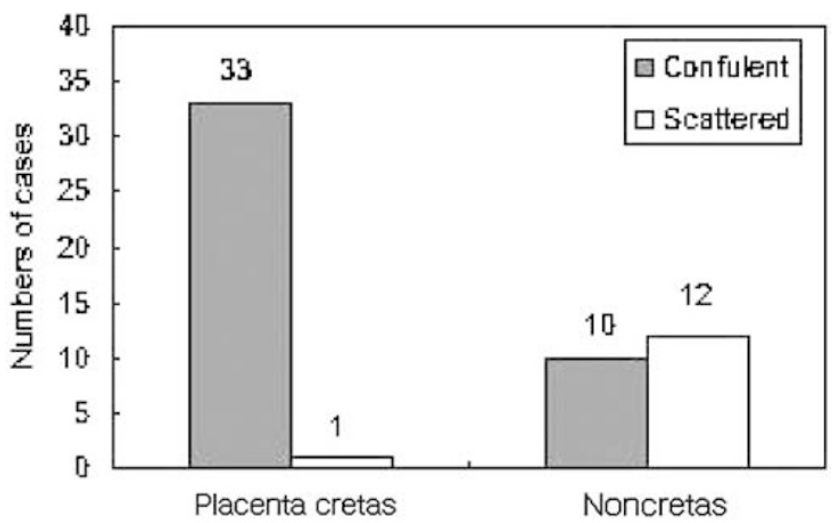

Figure 5 Incidence of 'confluent' and 'scattered' distribution of ISITs in placenta cretas and noncretas.

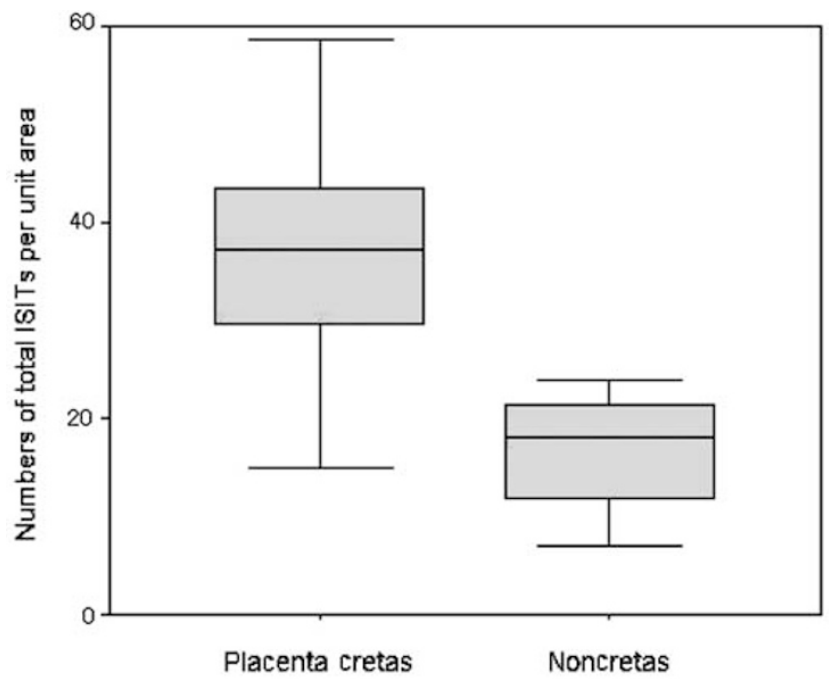

Figure 6 Total number of ISITs per unit area within the superficial myometrium of placenta cretas and noncretas. 

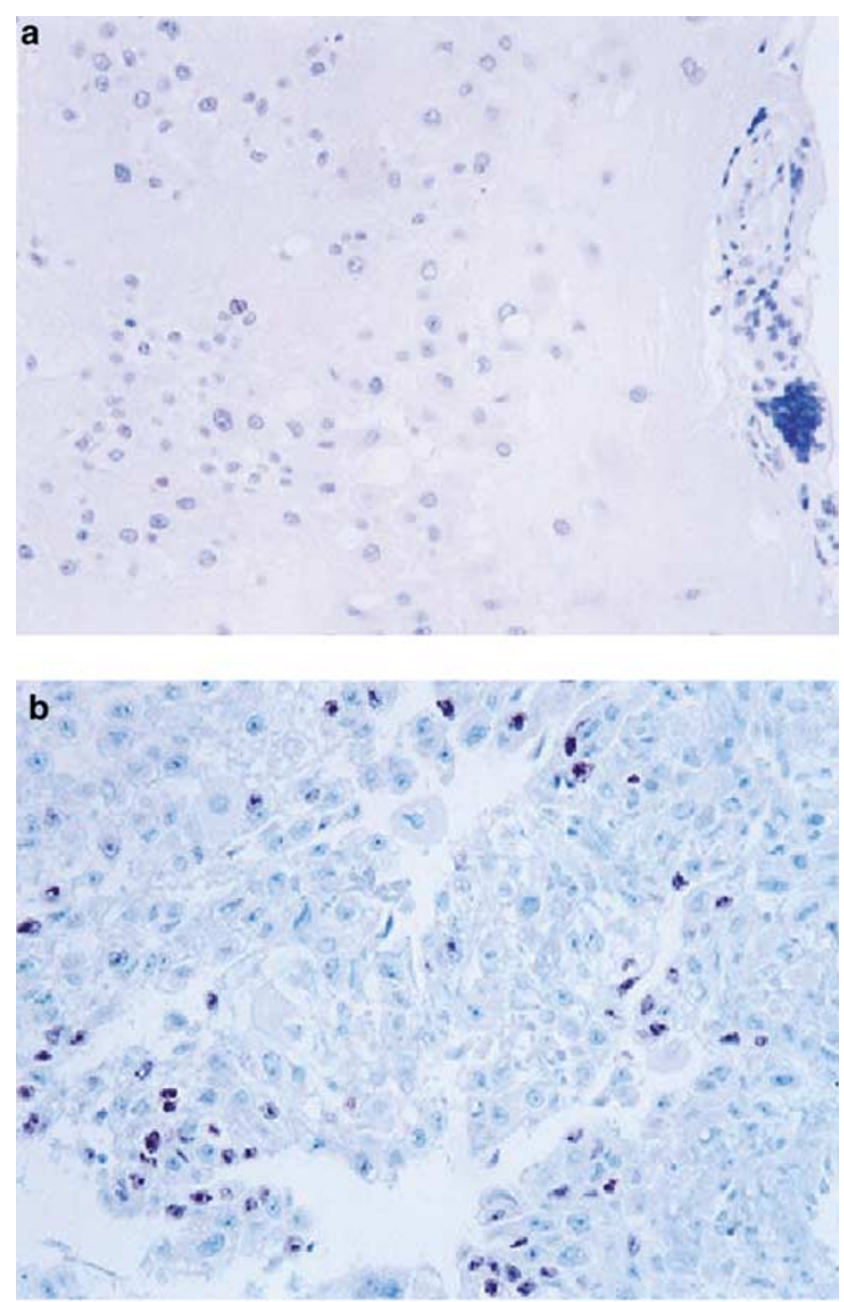

Figure 7 Immunohistochemical stains for Ki-67 in ISITs of (a) placenta cretas and (b) tubal pregnancy.

cells in the entire fields in 10 cases and a complete immunonegativity in the remaining 24 cases (Figure 7a). In noncretas, five cases showed one or two positive cells with the remaining 17 cases being completely negative. Ruptured sites of tubal pregnancies, however, showed up to $10 \%$ of ISITs being positively stained in the highest area, although staining with antibody varied from area to area (Figure 7b). No immunopositive cells were observed against antibodies to Bcl-2 and cleaved caspase-3 in any of the placenta cretas, noncretas, and tubal pregnancy samples.

\section{Discussion}

Placental implantation sites in normal and abnormal pregnancies are routinely invaded by a variable number of ISITs. In a normal gravid uterus, a few ISITs are scattered within the endometrium and superficial myometrium. In the exaggerated placental site, which can occur in a normal pregnancy or an abortion, the histological findings partly overlap with placenta cretas, in that there is exuberant infiltration of ISITs into the decidua and superficial myometrium, with chorionic villi frequently observed at the implantation site. In the exaggerated placental site, however, the overall architecture is not disturbed nor is the myometrium directly attached by villous tissue, ${ }^{6}$ whereas, in placenta cretas, there is irregular destruction or perforation accompanied by invasion of placental tissue. In tubal pregnancies, architecture of the implantation site is usually destroyed and the wall is replaced by sheets of ISITs as in placenta cretas, but the former has a more rapid process of invasion, resulting in rupture of the organ compared to the slow progression of invasion observed in the latter. We therefore hypothesized that abnormal placentation and the rate of destruction of implantation sites in various abnormal pregnancies would be related to the number, distribution pattern, or abnormally retained proliferative or invasive properties of ISITs.

Extravillous trophoblasts have been found to express either a proliferative or an invasive phenotype during differentiation. ${ }^{9,10}$ Cells with the proliferative phenotype are characterized by expression of proliferation markers, such as MIB-1, Ki-67, and EGFR ( $c$-erbB-1), and secretion of epithelial integrins such as $\alpha 6 \beta 4$, as well as exhibiting polar secretion of extracellular matrix. In contrast, cells with the invasive phenotype express proto-oncogene $c$-erbB-2, and interstitial integrins such as $\alpha 5 \beta 1, \alpha 1 \beta 1, \alpha v \beta 3$, and $\alpha v \beta 5$, as well as exhibiting apolar secretion of extracellular matrix, and upregulation of matrix metalloproteinases (MMPs). ${ }^{11-13}$ During normal placentation, the proliferative and invasive phenotypes are not usually coexpressed by the same cells, except in a transitional zone..$^{8,14,15}$ Timing of switching from proliferative to invasive phenotype seems to occur normally during very early pregnancy, ${ }^{9}$ although it has not been clearly defined. The noncretas group in our study, many of which would presumably have normal histologic features of implantation sites in the third trimester pregnancy, showed few ISITs within the superficial myometrium and near zero proliferating activity, suggesting that ISITs in the normal third trimester pregnancy not only lose their proliferative activity but also decrease in their number through an unidentified mechanism.

Recently, apoptotic indices obtained using the TUNEL assay and by immunostaining with antibody to cleaved caspase-3 were found to be well correlated, with the latter being an easy, sensitive, and reliable method for quantifying apoptosis. ${ }^{16}$ Using antibodies to the Ki-67, Bcl-2, and cleaved caspase3 , we observed no significant differences in the ISIT proliferation and apoptotic rates between placenta cretas and noncretas, despite the significant difference in their numbers. These observations indicate that the increase in ISITs observed in the placenta cretas was not due to increased proliferation or decreased cell death, but it may be due to the 
accumulation of ISITs that had irreversibly left the proliferative cell cycle but retained invasive properties.

Tubal pregnancy and placenta cretas have common aspects characterized by local deficiency of decidualization and increased ISITs in the implantation sites. The Ki-67 indices of ISITs of these two conditions, however, were quite different indicating that coexpression of the proliferative and invasive phenotypes may give rise to the rapid invasive growth of extravillous trophoblasts occurring in tubal pregnancy. ${ }^{14,15}$ In placenta cretas, expression of the invasive phenotype coupled with very low or absent proliferation indices may lead to gradual ingrowth of placental tissue, allowing the pregnancy to be maintained for a considerable period of time in many cases until the third trimester. ${ }^{17,18}$ Since the proliferating activities of ISITs are markedly decreased in normal and abnormal implantations in third trimester pregnancies, ${ }^{5}$ proliferating capacity itself does not seem to be the critical factor determining the invasive property of placental tissue in placenta cretas. Rather, an increase in the population of ISITs, due to aberrant or delayed switching from the proliferative to the invasive phenotype, may explain abnormal invasive growth.

It is not yet known how the increased population of ISITs leads to the invasive growth of placental tissue. It has been described that increased production of hyaluronic acid in the villous-maternal junction of placenta cretas facilitates cytotrophoblastic invasion by opening the extracellular matrix of decidual stroma. ${ }^{2}$ Increased activities of extracellular matrix-degrading proteinases, such as plasminogen activators, MMPs, and tissue inhibitors of MMPs (TIMPs) which are secreted by ISITs, are known to play important roles in regulating trophoblastic invasion in implantation. ${ }^{19}$ In our study, deciduas of normal postpartum uteri in the noncretas group contained numerous ISITs, but the number was abruptly decreased in the adjacent myometrium. Moreover, most of the ISITs, both in normal and abnormal implantations, invaded to a depth of $5.5 \mathrm{~mm}$ in the superficial myometrium, suggesting that the microenvironment, including decidual factors, may limit the depth of invasion with the invasive capability of these cells lost beyond a certain level within the myometrium.

Multinucleated cells have been regarded as degenerated extravillous trophoblastic cells. ${ }^{9}$ In our study, these cells were usually scattered in the deeper portion of the trophoblastic layer rather than the superficial or immediate subplacental zone. The numbers of multinucleated cells were not significantly different between the placenta cretas and noncretas groups, and, in both, the proliferation and apoptosis rates were virtually zero. These findings suggest that multinucleated ISITs are not active at the implantation sites, and that most are nonfunctional.
In conclusion, our findings suggest that the increased number of ISITs plays an important role in the placental ingrowth occurring during placenta cretas, but that the mechanism of the increment of these cells in this condition remains to be elucidated.

\section{References}

1 Gersell DJ, Kraus FT. Diseases of the placenta. In: Kurman RJ (ed). Blaustein's Pathology of the Female Genital Tract, 5th edn. Springer: New York, 2002, pp 1111-1113.

2 Earl U, Bulmer JN, Briones A. Placenta accreta: an immunohistological study of trophoblast populations. Placenta 1987;8:273-282.

3 Hutton L, Yang SS, Bernstein J. Placenta accreta. A 26year clinicopathologic review (1956-1981). NY State J Med 1983;83:857-866.

4 Shih IM. The role of CD146 (Mel-CAM) in biology and pathology. J Pathol 1999;189:4-11.

5 Shih IM, Kurman RJ. The pathology of intermediate trophoblastic tumors and tumor-like lesions. Int J Gynecol Pathol 2001;20:31-47.

6 Shih IM, Mazur MT, Kurman RJ. Gestational trophoblastic disease and related lesions. In: Kurman RJ (ed). Blaustein's Pathology of The Female Genital Tract, 5th edn. Springer: New York, 2002, pp 1235-1237.

7 Shih IM, Kurman RJ. Expression of melanoma cell adhesion molecule in intermediate trophoblast. Lab Invest 1996;75:377-388.

8 Shih IM, Kurman RJ. Ki-67 labeling index in the differential diagnosis of exaggerated placental site, placental site trophoblastic tumor, and choriocarcinoma: a double immunohistochemical staining technique using Ki-67 and Mel-CAM antibodies. Hum Pathol 1998;29:27-33.

9 Frank HG, Kaufmann P. Nonvillous parts and trophoblast invasion. In: Benirscheke K, Kaufmann P (eds). Pathology of the Human Placenta, 4th edn. Springer: New York, 2000, pp 171-272.

10 Kaufmann P, Castellucci M. Extravillous trophoblast in the human placenta. Trophoblast Res 1997;10:21-65.

11 Damsky $\mathrm{CH}$, Librach $\mathrm{D}$, Lim $\mathrm{K}-\mathrm{H}$, et al. Integrin switching regulates normal trophoblast invasion. Development 1994;120:3657-3666.

12 Damsky C, Sutherland A, Fisher S. Extracellular matrix 5: adhesive interactions in early mammalian embryogenesis, implantation and placentation. FASEB J 1993;7:1320-1329.

13 Jokhi PP, King A, Loke YW. Reciprocal expression of epidermal growth factor receptor (EGF-R) and c-erbB2 by non-invasive and invasive human trophoblast populations. Cytokine 1994;6:433-442.

14 Kemp B, Kertschanska S, Handt S, et al. Different placentation patterns in viable as compared with nonviable tubal pregnancy suggest a divergent clinical management. Am J Obstet Gynecol 1999;181:615-620.

15 Kertschanska S, Frank HG, Huppertz B, et al. Coexpression in integrins and their ligands in extravillous trophoblast and matrix-type fibrinoid of the human placenta. Placenta 1997;18:A32 (abstract).

16 Duan WR, Garner DS, Williams SD, et al. Comparison of immunohistochemistry for activated caspase-3 and cleaved cytokeratin18 with the TUNEL method for 
quantification of apoptosis in histological sections of PC-3 subcutaneous xenografts. J Pathol 2003;199: 221-228.

17 Miller DA, Chollet JA, Goodwin TM. Clinical risk factors for placenta previa-placenta accreta. Am J Obstet Gynecol 1997;177:210-214.
18 Weekes LR, Greig LB. Placenta accreta. A twenty-year review. Am J Obstet Gynecol 1972;113:76-82.

19 Behrendtsen O, Alexander CM, Werb Z. Metalloproteinases mediate extracellular matrix degradation by cells from mouse blastocyst outgrowths. Development 1992;114:447-456. 